American Journal of Applied Sciences 7 (3): 434-437, 2010

ISSN 1546-9239

(C) 2010Science Publications

\title{
Deoiling and Regeneration Efficiencies of Spent Bleaching Clay
}

\author{
${ }^{1}$ A.W. Nursulihatimarsyila, ${ }^{1}$ K.Y. Cheah, ${ }^{2}$ T.G. Chuah, ${ }^{1}$ W.L. Siew and ${ }^{2}$ T. S.Y. Choong \\ ${ }^{1}$ Malaysian Palm Oil Board, P.O. Box 10620, 50720 Kuala Lumpur, Malaysia \\ ${ }^{2}$ Department of Chemical and Environmental Engineering, \\ University Putra Malaysia, 43400 Serdang, Selangor, Malaysia
}

\begin{abstract}
Problem statement: Disposal and reuse of Spent Bleaching Clay (SBC) from palm oil processing industry is a problem of growing importance. The residual oil in the SBC can be recovered using hexane as solvent. Approach: In this study, the effect of different solid to solvent ratio on the deoiling efficiency of SBC samples from palm oil refinery and palm kernel refinery were studied. The amount of extracted oil and deoiling efficiency for both types of SBC increases as the solid to solvent ratio is decreased. Results: All the extracted oils, irrespective of the amount of solvent used, have poorer quality than crude oil and may be difficult to be refined to good quality and stability. Conclusion: The deoiled SBC treated using different solid to solvent ratio gave almost similar regeneration efficiency i.e., about $80 \%$ for bleaching of $\mathrm{CPO}$ and not more than $30 \%$ for bleaching of CPKO.
\end{abstract}

Key words: Spent bleaching clay, deoiling, regeneration, crude palm oil, crude palm kernel oil

\section{INTRODUCTION}

Refining of crude palm oil involves degumming, bleaching and deodorizing. The purpose of bleaching is to remove undesirable substances such as soap residues, trace of heavy metals, phosphorus compound, as well as colored matter (i.e., carotenoids and chlorophyll pigments).

The Spent Bleaching Clay (SBC), containing 30$40 \%$ oil, is generally disposed untreated. The disposal of SBC in landfills may cause fire and pollution hazards due to the substantial oil content in the clay. This disposal constituted a significant economic waste and an environmental burden. By recovering the oil, the cost of the disposal will be reduced effectively and the recovered oil may be reused (Ong, 1983; Pollard et al., 1993; Waldmann and Eggers, 1991).

The present study investigates the effect of solvent to solid ratio on the deoiling efficiency as well as the regeneration efficiency of the deoiled SBC on refining of CPO and CPKO. The quality of the extracted oil is studied.

\section{MATERIALS AND METHODS}

SBC samples were obtained from FELDA Palm Oil Refinery, Kuantan, Pahang. SBC collected from palm oil and palm kernel oil refineries were coded as Sample 1 (S1) and Sample 2 (S2), respectively. Non- polar solvent hexane was used as a standard solvent for the extraction process. Theoretically hexane allowed the use of the extracted oil in food (Lee et al., 2000). The ratio of solid to solvent (wt/wt) was varied from 1:1- :7. In this study, $10 \mathrm{~g}$ of SBC was used. For first extraction stage, the mixture of SBC (solid) and hexane (solvent) was shaken in a water bath for $30 \mathrm{~min}$ at $40^{\circ} \mathrm{C}$. The hexane layer was then separated and evaporated using rotary vacuum evaporator. The extraction was repeated until no further increase in weight of the extracted materials was detected. The percentage of deoiling efficiency was determined as:

Deoiling efficiency $(\%)=\frac{\mathrm{W}_{\mathrm{be}}}{\mathrm{W}_{\mathrm{se}}} \times 100 \%$

where, $\mathrm{W}_{\mathrm{be}}$ and $\mathrm{W}_{\mathrm{se}}$ are the weight of the oil extracted using batch extraction and the weight of oil extracted using conventional Soxhlet extractor at temperature of $60^{\circ} \mathrm{C}$ for $8 \mathrm{~h}$, respectively.

About $10 \mathrm{~g}$ of sample was placed into the thimble and covered by gauze at the top of sample layer. Hexane solvent was placed in round bottom flask. The solvent was evaporated and separated by rotary vacuum evaporator and the amount of oil extracted was measured. The quality of oil determined includes specific extinction in UV-light, trigylceride composition and fatty acid composition.

Corresponding Author: T.S.Y. Choong, Department of Chemical and Environmental Engineering, University Putra Malaysia, 43400 Serdang, Selangor, Malaysia 
Am. J. Applied Sci., 7 (3): 434-437, 2010

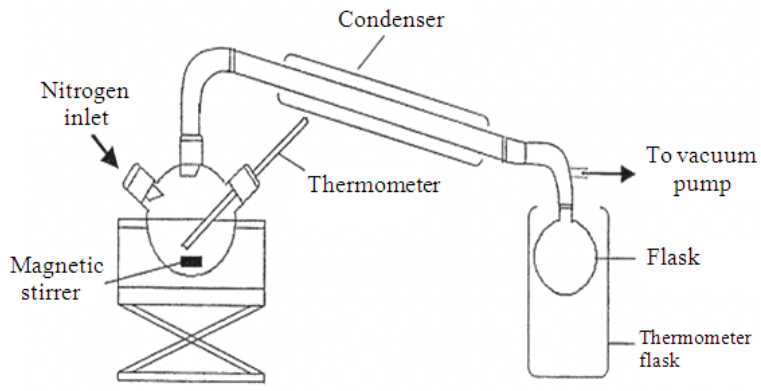

Fig. 1: Apparatus set-up for the laboratory bleaching process

Deoiled SBC samples were dried at $120^{\circ} \mathrm{C}$ for $8 \mathrm{~h}$. The deoiled SBC was used for refining $\mathrm{CPO}$ and $\mathrm{CPKO}$ following the Seed Crushers and Oil Producer's Association (SCOPA) bleachability test to obtain its performance. The apparatus set up is shown in Fig. 1. Color was an important quality of refined oil and was used here to determine the regeneration efficiency of the SBC. The regeneration efficiency was calculated as:

Regeneration efficiency $(\%)=\frac{R_{o}-R_{d}}{R_{o}-R_{f}} \times 100 \%$

where, $R_{0}, R_{d}$ and $R_{f}$ are the red color values of unbleached oil, oil bleached by deoiled SBC and oil bleached by fresh bleaching clay, respectively.

\section{RESULTS AND DISCUSSION}

The basic test performed for quality control of oil are contents of Free Fatty Acids (FFA), specific extinctions at UV wavelengths of 233 and $269 \mathrm{~nm}$, Deterioration Of Bleachability Index (DOBI), Iodine Value (IV), fatty acid and trigylceride compositions and minor constituents such as chlorophyll and carotenoids. Free fatty acid content and DOBI are required in the trading of oil. Table 1 shows that the FFA content and primary and secondary oxidation products of oils extracted from SBC are higher compared to values found in crude oils.

FFA is the most important parameter of crude oil quality used in refining process. The FFA in the CPO and CPKO are 3.26 and $2.47 \%$, respectively. These are within the typical values of FFA in Malaysian CPO and CPKO, i.e. 3.2 and $2.5 \%$, respectively. The oil extracted from SBC has much higher FFA, i.e. 20.5 and $13.49 \%$ in EPO and EPKO, respectively. This deterioration of quality arises because of hydrolysis of the residual oils (Ooi et al., 1994; Kheang et al., 2006).
Table 1: Characteristic of crude oil and oil extracted from SBC

\begin{tabular}{lrrrr}
\hline Parameter & EPO & \multicolumn{1}{c}{ CPO } & EPKO & CPKO \\
\hline Oil recovery (\%) & $8-26$ & - & $9-35$ & - \\
FFA (\%) max & 20.57 & 3.26 & 13.49 & 2.47 \\
$\mathrm{E}_{233}^{\mathrm{1 \%} \max }$ & 3.20 & 1.83 & 2.00 & 1.28 \\
$\mathrm{E}_{269}^{\mathrm{I} \%} \max$ & 1.50 & 0.80 & 0.50 & 0.25 \\
Carotene content (ppm) & 41.00 & 555.09 & 13.00 & 20.00 \\
DOBI & $<0.10$ & 2.80 & $<0.05$ & 0.06 \\
IV & $\approx 53.00$ & 54.60 & 14.00 & 19.80 \\
\hline
\end{tabular}

Note: EPO: Oil extracted from SBC obtained from palm oil refinery EPKO: Oil extracted from SBC obtained from palm kernel oil refinery

Table 2: Characteristic of crude oil and oil extracted from SBC

\begin{tabular}{lrrrr}
\hline Sample & CPO & EPO & CPKO & EPKO \\
\hline C8:0 & 0.0 & 0.0 & 3.8 & 3.6 \\
C10:0 & 0.0 & 0.0 & 3.4 & 3.7 \\
C12:0 & 0.2 & 0.2 & 47.0 & 50.0 \\
C14:0 & 1.2 & 1.1 & 15.7 & 15.5 \\
C16:0 & 42.6 & 43.4 & 8.3 & 7.7 \\
C18:0 & 3.8 & 4.2 & 2.1 & 2.0 \\
C18:1 & 40.4 & 39.2 & 16.2 & 13.4 \\
C18:2 & 10.8 & 10.1 & 2.8 & 2.4 \\
C20:0 & 0.0 & 1.2 & 0.0 & 0.0 \\
\hline
\end{tabular}

Note: EPO: Oil extracted from SBC obtained from palm oil refinery; EPKO: Oil extracted from SBC obtained from palm kernel oil refinery

The specific extinction coefficients at $233 \mathrm{~nm}$ and $269 \mathrm{~nm}$ correspond to the presence of primary and secondary oxidation products, respectively, with a higher value of absorbance indicating a larger amount of oxidation products. Table 1 shows that the specific extinction coefficient at 233 and $269 \mathrm{~nm}$ of EPO is 3.2 and 1.5, which is higher than CPO of 1.83 and 0.80 , respectively. These results indicate that the EPO contained a larger amount of primary and secondary oxidation products than the CPO. Similar conclusion can be reached for CPKO.

CPO contains typically 555 ppm of carotenoids and appears as orange red in color. Meanwhile, CPKO is deep yellow in color with approximately $20 \mathrm{ppm}$ of carotenoids. The carotene content in EPO and EPKO are found to be 41 and $13 \mathrm{ppm}$, respectively, which are obviously much lower than the crude oil. The carotene compounds could be bounded strongly in the pore of spent bleaching clay. Iodine Value (IV) is a measure of unsaturation of fats and oils. IV of EPO is 53 and EPKO is 14, which is lower than the value of 54.6 of CPO and 19.8 of CPKO, respectively. However, the difference in IV between extracted oil and crude oil is not obvious. The extracted oil from both the SBC are slightly more saturated than CPO and CPKO. 


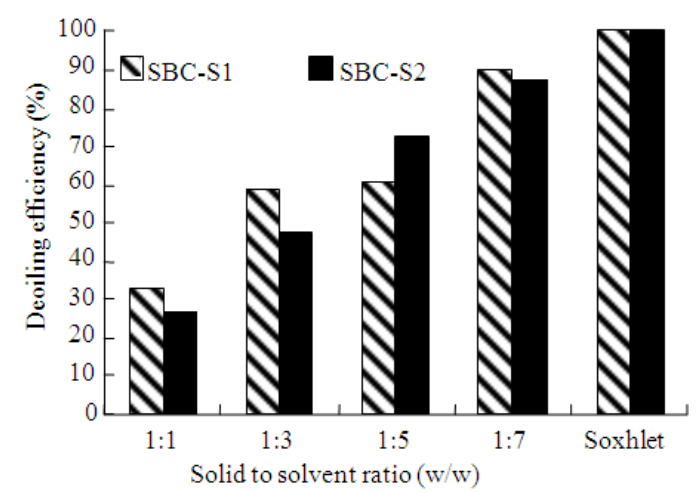

Fig. 2: Deoiling efficiency as a function of solid to solvent ratios

Palm oil is characterized by its high level of palmitic acid (C16:0), approximately 39.2-45.8\% (Kheang et al., 2006). Palm kernel oil is richer in lauric acid (C12:0), about 48\% (Kheang et al., 2006). Table 2 shows the fatty acid composition of both crude oils and extracted oils. The result indicated that the bleaching process has very little effect on the fatty acid composition of the crude and extracted oil.

The effect of various ratios of solid to solvent on the extraction of palm oil and palm kernel oil from SBC is investigated by employing the batch extraction method. A conventional modified Soxhlet extraction is used as a reference, in which $100 \%$ of the residual oil is extracted. Deoiling efficiency and regeneration efficiency of Deoiled Spent Bleaching Clay (DSBC) is determined. Deoiling efficiency is employed to determine the amount of residual oil that can be removed from SBC using solvent extraction. Regeneration efficiency is used to determine the capability of deoiled SBC in removing color pigments of oil, as compared to fresh bleaching clay.

Two types of SBC are used, i.e. from palm oil refinery (SBC-S1) and from palm kernel oil refinery (SBC-S2). The deoiling efficiencies for various ratios of SBC to hexane (1:1, 1:3, 1:5 and 1:7) are presented in Fig. 2.

The SBC to hexane ratios influenced strongly the deoiling efficiency. The deoiling efficiency for both SBC-S1 and SBC-S2 increases as the solid to solvent ratio is decreased. The maximum deoiling efficiencies (at solid to solvent ratio of 1:7) are 90 and $87 \%$ for SBC-S1 and SBC-S2, respectively. In contrast, only $32.6 \%$ and $26.8 \%$ of deoiling efficiency is achieved for SBC-S1 and SBC-S2, respectively, using solid to solvent ratio of $1: 1$. The amount of oil extracted from SBC-S1 and SBC-S2 using Soxhlet extraction are 2.58 and $3.47 \mathrm{~g}$, respectively.

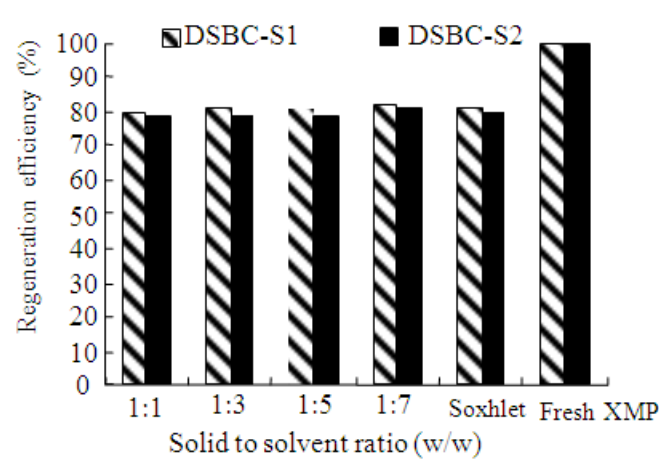

(a)

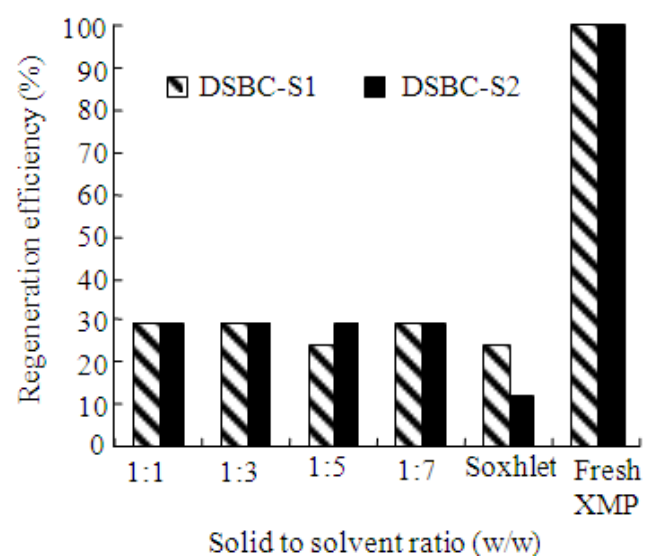

(b)

Fig. 3: Regeneration efficiency as a function of solid to solvent ratios in the refining of (a) CPO and (b) CPKO

The regeneration efficiency is calculated using Eq. 2. The regeneration efficiency of DSBC-S1 and DSBC-S2 in the CPO refining is significantly higher compared to the refining of CPKO, i.e. about $80 \%$ for $\mathrm{CPO}$ and $30 \%$ for CPKO (Fig. 3).

\section{CONCLUSION}

The quality of the oil extracted from SBC is inferior to crude oil. The FFA content and the degree of oxidation product (i.e. conjugated dienes and conjugated trienes) of the oil are higher, the DOBI value is lower and the oils are deep brownish for EPO and yellowish for EPKO in color appearance. The results indicate that the oil extracted from SBC may be difficult to be refined to good quality and stability. The amount of extracted oil and deoiling efficiency for both SBC increases as the solid to solvent ratio is decreased. However, the regeneration efficiency of deoiled SBC 
treated using different solid to solvent ratio gave almost similar regeneration efficiency, i.e. about $80 \%$ for bleaching of CPO and not more than $30 \%$ for bleaching of CPKO.

\section{REFERENCES}

Lee, C.G., C.E. Seng and K.Y. Liew, 2000. Solvent Efficiency for oil extraction from spent bleaching clay. J. Am. Oil Chem. Soc., 77: 1219-1222. DOI: 10.1007/s11746-000-0190-6

Kheang, L.S., C.S. Foon, C.Y. May and M.A. Ngan, 2006. A study of residual oils recovered from spent bleaching earth: Their Characteristics and Applications. Am. J. Appl. Sci., 3: 2063-2067.

Ong, J.T.L., 1983. Oil Recovery from Spent Bleaching Earth and Disposal of the Extracted Material. J. Am. Oil Chem. Soc., 60: 314-315. DOI: 10.1007/BF02543510
Ooi, T.L., M. Badri and D. Asma, 1994. A study of the nature of oil recovered from spent earth obtained from the physical refining of palm oil. Elaeis, 6: 109-116.

Pollard, S.J.T., J.C. Sollars and R. Perry, 1993. The reuse of spent bleaching earth: A feasibility study in waste minimisation for the edible oil industry. Bioresour. Technol., 45: 53-58. DOI: 10.1016/0960-8524(93)90143-Y

Waldmann, C. and R. Eggers, 1991. Deoiling contaminated bleaching clay by high pressure extraction. J. Am. Oil Chem. Soc., 68: 922-930. DOI: $10.1007 / \mathrm{BF} 02657536$ 